\title{
Intraoperative low field MRI in transsphenoidal pituitary surgery
}

\author{
Morten Winkler Møller ${ }^{1,2}$, Marianne Skovsager Andersen ${ }^{2,3}$, Christian Bonde Pedersen ${ }^{1,2}$, \\ Bjarne Winther Kristensen ${ }^{2,4}$ and Frantz Rom Poulsen ${ }^{1,2}$ \\ 'Department of Neurosurgery, Odense University Hospital, Odense C, Denmark \\ ${ }^{2}$ Clinical Institute, University of Southern Denmark, Odense C, Denmark \\ ${ }^{3}$ Department of Endocrinology, Odense University Hospital, Odense C, Denmark \\ ${ }^{4}$ Department of Pathology, Odense University Hospital, Odense C, Denmark
}

Correspondence should be addressed to M W Møller: morten_wm@hotmail.com

\begin{abstract}
Background: Intraoperative low field MRI (iMRI, 0.15T) during transsphenoidal surgery on pituitary adenomas (PAs) may significantly improve tumor removal. However, extensive surgery can lead to pituitary hormone deficiency. Furthermore, introduction of iMRI will prolong duration of surgery, which may elevate risk of postoperative infections.

Methods: Overall, 180 transsphenoidal surgeries for PAs from 2007 to 2015 were included. IMRI was available from 2011 to 2015, during this period 67/78 (86\%) surgeries were with iMRI (iMRI, $n=67$ ). A total of 113 surgeries were performed without iMRI (controls). All surgical procedures were performed by microscopic technique. Tumor size, hormonal status and vision were assessed before surgery and 3-5 months postoperatively.

Results: Gross total resection (GTR), mean tumor remnant volume and $\Delta$-volumes were comparable between iMRI and controls: $15 \%(10 / 66)$ vs $23 \%(26 / 109)(P=0.17), 2.97 \mathrm{~cm}^{3}$ $(0.9-5)$ vs $2.1 \mathrm{~cm}^{3}(1.6-2.6)(P=0.3)$ and $4.5 \mathrm{~cm}^{3}(3.6-5.5)$ vs $5.1 \mathrm{~cm}^{3}(4.2-6)(P=0.4)$, respectively. Duration of surgery was significantly longer during iMRI vs controls: $126 \mathrm{~min}$ $(117-135)$ vs $98 \mathrm{~min}(92-103)(P<0.001)$. New pituitary-adrenal deficiency in iMRI vs controls was seen in $35 \%(17 / 48)$ and $35 \%(23 / 66)$ of surgeries, respectively $(P=0.95)$. New thyroid deficiency was found in 33\% (13/29) and $41 \%(28 / 69)$ and visual field deficiencies improved in 44\% (19/43) and 38\% (23/60) in iMRI vs controls, respectively $(P>0.1)$. Conclusion: Tumor remnant after pituitary surgery was not significantly reduced using intraoperative low field MRI. Duration of surgery was increased in iMRI, but was not associated with increased infection rate. Pituitary hormonal function and vision were comparable between iMRI and controls.
\end{abstract}

\author{
Key Words \\ - intraoperative MRI \\ - transsphenoidal \\ - microscopic \\ - pituitary \\ - surgery
}

\section{Introduction}

Pituitary adenomas (PAs) account for 10-25\% of intracranial tumors $(1,2,3)$. They arise from adenohypophyseal cells, despite their benign nature, 25-55\% of PAs show invasive growth (4), expanding into suprasellar (5), infrasellar and/or parasellar regions (6). Pressure on neighboring structures, including anterior

http://www.endocrineconnections.org https://doi.org/10.1530/EC-18-0140

() 2018 The authors Published by Bioscientifica Ltd pituitary cells, optic chiasma and adjacent nerves in cavernous sinus may cause hypopituitarism (7), vision field impairment and/or ophthalmoplegia (8).

For other PAs, except prolactinomas, surgery is the first choice of treatment. The primary surgical technique has been transsphenoidal surgery since Hardy introduced

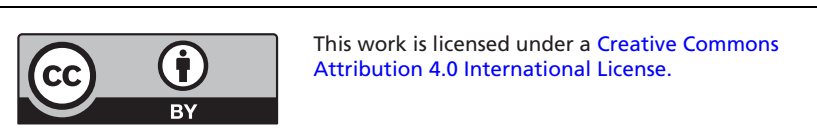


surgical microscopes in 1962 (9). Further development of this technique has improved gross total resection rate (GTR) (10). Intraoperative low field MRI (iMRI) has been proven useful for visualizing tumor remnant during surgery (11). iMRI may improve and facilitate GTR (leaving no adenoma remnant on postoperative MRI) as iMRI has been used, successfully, for other intracerebral tumors, such as gliomas (12).

In general, surgical risk includes postoperative anterior hypopituitarism or impaired vision, especially in macroadenomas ( $\geq 10 \mathrm{~mm}$ ). Additionally, rhinoliquorrhea and diabetes insipidus (DI) are common complications $(13,14)$.

PAs are classified into clinically non-functioning pituitary adenomas (NFPAs) to clinical prolactinoma (PRL)-, adrenocorticotropic hormone (ACTH)-, growth hormone $(\mathrm{GH})$ - or thyroid-stimulating hormone (TSH)secreting adenomas (15).

Previous studies reported that iMRI augmented adequate resection of PAs $(16,17)$, but no studies have investigated whether presumed increased resection using iMRI is correlated with postoperative pituitary function and vision improvement.

The purpose of this retrospective study was to determine whether low field iMRI during transsphenoidal pituitary surgery significantly (1) improved tumor resection, (2) augmented pituitary hormone deficiency and/or (3) influenced (post)operative complications.

\section{Methods}

\section{Study design}

In this retrospective cohort study, the inclusion criteria were transsphenoidal surgery for PA from 2007 to 2015. Patients were identified using the Patient Registry and ICD-10 diagnostic code D352 combined with surgical code AAE10. A low field iMRI (Medtronic, Polestar 0.15T) was installed at the department of neurosurgery in the fall of 2011 and used for all cases of transsphenoidal surgery, except in a few cases of scanner malfunction or where patient stature were incompatible with the scanner. Patients were stratified into two patient cohorts operated with and without (control group) use of iMRI (iMRI). All surgical procedures were performed by the same two neurosurgeons. Both surgeons were experienced and performed the procedures routinely throughout this period.

http://www.endocrineconnections.org https://doi.org/10.1530/EC-18-0140

(๑) 2018 The authors Published by Bioscientifica Ltd

\section{Surgical technique}

After induction of general anesthesia, a standard microscope (Zeiss, Pentoro) and neuronavigation (Medtronic, Minneapolis, MN, USA)-guided submucosal paraseptal transsphenoidal microsurgical technique was used in all patients. Adenomas were removed using blunt currettes. After adenoma removal, hemostasis was achieved with temporary placement of Spongostan and, if necessary, Surgiflo or FlowSeal. Dura was closed using Tachoseal and in some cases the sellar floor was reconstructed using titanium mesh or septal bone. The nasal septum was repositioned and fixed with nasal packing for 12-24h. Lumbar drainage was not used routinely.

In the iMRI group, the patient's head was fixed in a dedicated titanium head holder with MR coil (Medtronic). A preoperative T1 iMRI scan without contrast was performed immediately prior to surgery and at least one iMRI scan was performed during surgery (T1 with intravenous contrast, Dotarem). The first iMRI was performed when resection was considered adequate by the surgeon. If the scan showed accessible tumor remnant, an additional attempt to remove tumor was made. All patients were admitted to a semi-intensive neurosurgical ward for postoperative monitoring. If there were no perioperative surgical complications, patients were routinely transferred to the endocrinology ward the following day.

\section{Data collection}

\section{Magnetic resonance imaging}

Knosp (6) and Hardy (5) classifications were used to classify adenoma extension based on the patients preoperative MRI (1.5 or $3 \mathrm{~T})$. Tumor volume was calculated using 3D volumetric analysis in Horos on basis of axial, frontal or sagittal sections on T1-weighted images with contrast. Similarly, tumor remnant volume was calculated on routine follow-up MRI scans performed 4-6 months after surgery. Duration of surgery and complications within 30 days were registered. All image analysis was performed blinded to the observer with respect to usage of iMRI.

Assessment of the preoperative and postoperative MRIs was performed blinded to the observer concerning the use of iMRI, pituitary function and vision impairment. Cases with uncertainty concerning tumor delineation were discussed with senior neurosurgeons. 
analyzed using Student's t-test and chi-squared test (STATA/IC 15.0).

\section{Ethics}

The study was approved by the Danish Patient Safety Authority (ID 3-3013-1765/1/) and the Danish Data Protection Agency (ID 16/25477). The Danish Patient Safety Authority allowed us to use patient journal information without the consent of each patient. It was approved on 8/7/2016, with case number: 3-3013-1765/1/. s-cortisol and Synacthen test). Deficiency in either axis was defined as biochemical data outside reference values for the specific hormone or if patients were already on substitution therapy. Intact function was defined as hormone levels within the normal range, whereas increased values for IGF-1, cortisol or T4 lead to specific tests for secreting adenomas. After initial screening for a prolactinoma, the adenoma was clinically divided into NFPA, ACTH-secreting adenomas (hypercortisolism defined by elevated 24-h urinary free cortisol, nonsuppressability of cortisol after $1 \mathrm{mg}$ of dexamethasone overnight to $>50 \mathrm{nmol} / \mathrm{L}$ and if required inferior petrosal sinus sampling to localize the PA or a GH-secreting adenoma (no suppression of GH to $<1 \mu \mathrm{g} / \mathrm{L}$ after an OGTT and elevated IGF-I). The exact diagnosis was based on the postoperative pathological and immunohistochemical analysis.

After surgery, the patients were monitored for development of DI. Postoperative pituitary function was assessed 6 weeks after surgery.

\section{Vision}

Vision was evaluated in all patients able to cooperate. Visual field was evaluated by quadrant affected (upperlower temporal/upper-lower nasal). This was combined with mean deviation (MD) measured in decibel (dB) for each eye, both pre- and postoperatively. Central vision deficiency was evaluated by rapidly declined vision by Snellens board or blindness. Based on MD, vision was categorized as intact vision, field vision deficiency or central vision impairment or combinations thereof.

\section{Statistical analysis}

All data were entered into a REDcap database (a secure web application for building and managing online surveys and databases) (18), with assistance from OPEN (OPEN Odense Patient Data Explorative Network) and

\section{Results}

\section{Patient inclusion}

196 operations were performed during 2007-2015. Sixteen cases were excluded since either no preoperative MRI scan in $(8 / 16)$ or in $(2 / 16)$ cases no surgical description was available (Fig. 1, PRISM diagram). Three out of 16 were primarily operated with a transcranial approach due to extensive suprasellar expansion of the adenoma. The last three cases had acute transcranial surgery during the immediate postoperative period due to expanding intrasellar hematoma or excessive rhinoliquorrhea. During 2011-2015, 86\% (67/78) surgeries were performed using iMRI (iMRI, $n=67$ ). During the time period 2007-2015, 113 patients were operated without the use of iMRI leaving a total of 180 patients included in this study

\section{Resection}

GTR was achieved in 15\% (10/66) in the iMRI group vs $23 \%(25 / 109)$ in the control group, $P=0.26$, chi-squared. The mean tumor remnant volume on the postoperative MRI was $2.97 \mathrm{~cm}^{3}(0.9-5)$ in the iMRI group vs $2.1 \mathrm{~cm}^{3}$ (1.6-2.6) in the control group. The mean resected tumor volume ( $\Delta$-volume) was $4.5 \mathrm{~cm}^{3}(3.6-5.5)$ vs $5.1 \mathrm{~cm}^{3}$ (4.2-6), respectively (Fig. 2 and Table 2).

Adenoma extension was classified by Knosp and Hardy classifications as shown in the Supplementary Table 1 (see section on supplementary data given at the end of this article). Adenomas were grouped by the Knosp classification into 0-2 and 3-4. Comparison between the iMRI group and the control group showed no difference in the amount of (GTR), mean remnant volume or $\Delta$-volume (Table 3). (Fig. 1; Table 1). 
Inclusion of patients

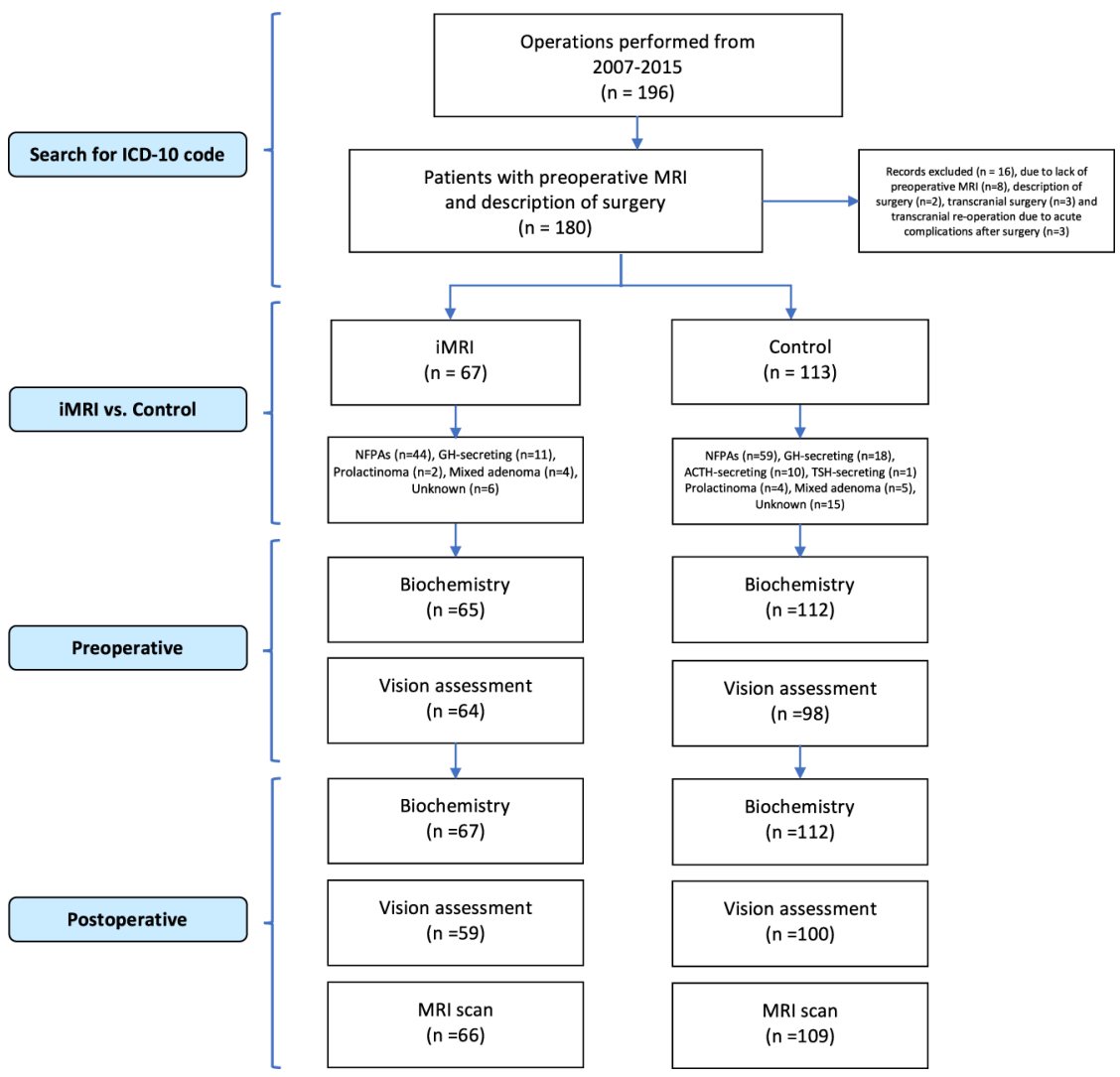

Figure 1

PRISMA diagram.

The duration of surgery was significantly longer in the iMRI group (126min range: 117-135) compared to the control group (98min range: $92-103$ ), $P$ value $<0.001$. However, there was no difference in the rate of complications 30 days postoperatively between the two groups. Complications included lung embolism, meningitis or rhinoliquorrhea (Table 2).

\section{Pituitary function}

HPA axis was intact in 115 cases preoperatively. Of these, $63 \%(31 / 48)$ of the iMRI group remained intact after surgery vs $65 \%(43 / 66)$ in the control group, $P=0.95$. In $15 \%(7 / 47)$ of the cases preoperative lost function was regained after surgery; $20 \%(3 / 15)$ in the iMRI group vs $12.5 \%(4 / 32)$ in the control group (Fig. 3). HPT axis was intact in 108 cases preoperatively, whereas postoperatively $66 \%(26 / 39)$ patients of the iMRI group vs 59\% (43/69) of the controls were intact in this axis, $P=0.46$ (Table 4 ). One case in the control group regained normal thyroid function after surgery.

Patients who were intact in both HPA and HPT axes postoperatively showed a surgical reduction in adenoma volume by $3.8 \mathrm{~cm}^{3}$ (95\% CI: $2.8-4.9$ ), while in those with deficient function in both these axes had adenoma volume reduced by $4.8 \mathrm{~cm}^{3}$ (95\% CI: 3.6-5.1), $P$-value $=0.22$.

\section{HPG axis}

The cohorts consisted of 32 males and 35 females in the iMRI group vs 64 males and 49 females in the controls group. 26\% (9/35) patients in the iMRI group were fertile women vs $47 \%(21 / 49)$ in the control group. In the iMRI group 67\% (6/9) women had regular menstrual cycles vs $52 \%(11 / 21)$ in the control group, and $33 \%$ $(3 / 9)$ had irregular menstrual cycles in the iMRI group vs $48 \%(10 / 21)$ in the control group postoperatively, $P=0.93$. Table 4 shows the distribution of menstruation status before and after surgery. There were no differences between the groups.

The males were divided into groups based on their testosterone level. This shows that $42 \%(10 / 24)$ males in the iMRI group had normal testosterone levels postoperatively, compared to $48 \%$ (23/48) in the control group.

In summary, there were no statistical significant difference in postoperative pituitary function between the iMRI group and the control group. http://www.endocrineconnections.org https://doi.org/10.1530/EC-18-0140 (c) 2018 The authors Published by Bioscientifica Ltd

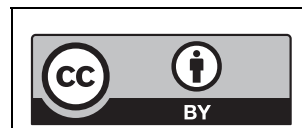

This work is licensed under a Creative Commons Attribution 4.0 International License. 
Table 1 Characteristics.

\begin{tabular}{|c|c|}
\hline Characteristics & \\
\hline$n$ & 180 \\
\hline \multicolumn{2}{|l|}{ Gender } \\
\hline Male/female & $96 / 84$ \\
\hline Median age at surgery (years) (range) & $58(17-87)$ \\
\hline Primary operation & $161(89.4)$ \\
\hline Re-operation & $16(8.9)$ \\
\hline Multiple re-operation & $3(1.7) *$ \\
\hline \multicolumn{2}{|l|}{ Pituitary function } \\
\hline \multicolumn{2}{|l|}{ HPA axis } \\
\hline Intact & $115(63.9)$ \\
\hline Deficient & $47(26.1)$ \\
\hline Unknown & $8(4.5)$ \\
\hline Cushing's & $10(5.6)$ \\
\hline \multicolumn{2}{|l|}{ HPT axis } \\
\hline Intact & $109(60.6)$ \\
\hline Deficient & $60(33.3)$ \\
\hline Unknown & $7(3.9)$ \\
\hline Elevated T4 & $4(2.2)$ \\
\hline \multicolumn{2}{|l|}{ HPG axis } \\
\hline Intact & 75 (41.7) \\
\hline Deficient & $95(52.8)$ \\
\hline Unknown & $10(5.5)$ \\
\hline \multicolumn{2}{|l|}{ ADH status } \\
\hline Intact & $176(97.7)$ \\
\hline Deficient & $4(2.3)$ \\
\hline \multicolumn{2}{|l|}{ Axes deficient $(\%)$} \\
\hline 0 & 53 (29.4) \\
\hline 1 & $42(23.3)$ \\
\hline 2 & $29(16.1)$ \\
\hline 3 & $27(15)$ \\
\hline Unknown & $29(16.1)$ \\
\hline \multicolumn{2}{|l|}{ Type of pituitary adenoma } \\
\hline NFPA & $103(57.2)$ \\
\hline GH secreting & $29(16.1)$ \\
\hline ACTH secreting & $10(5.6)$ \\
\hline TSH secreting & $1(0.6)$ \\
\hline Prolactinoma & $6(3.3)$ \\
\hline Mixed adenoma & $9(5)$ \\
\hline Other anomaly in sella & $11(6.1)$ \\
\hline Pituitary apoplexy & $7(3.7)$ * \\
\hline Unknown & $11(6.1)$ \\
\hline \multicolumn{2}{|l|}{ Vision } \\
\hline None & $60 / 50$ \\
\hline Field & $103 / 107$ \\
\hline Central & $13 / 15$ \\
\hline
\end{tabular}

*Two patients had three surgical procedures and a single patient underwent five operations. Pituitary apoplexia were found among the other adenomas.

\section{GH-secreting adenomas}

Eleven in the iMRI group vs 18 in the control group were operated due to a GH-secreting adenoma. 9\% (1/11) in the iMRI group were microadenomas vs $17 \%(3 / 18)$ in the control group. All of them had increased GH and IGF-1 values preoperatively and lack of suppression of GH during OGTT.

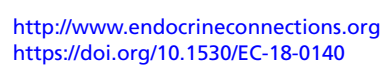

(c) 2018 The authors Published by Bioscientifica Ltd

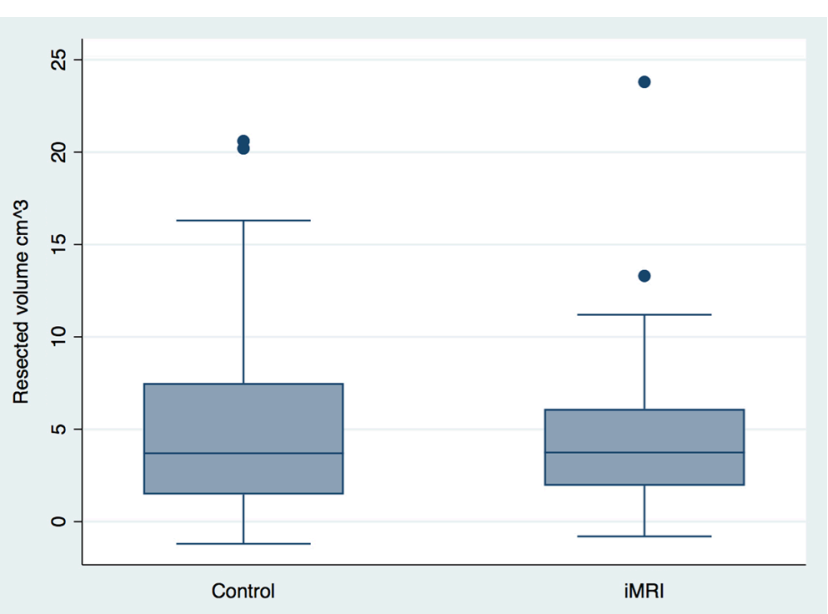

Figure 2

$\Delta$-volume box-plot.

Six weeks after surgery, 36\% (4/11) in the iMRI group had normal IGF-1 values and sufficient GH suppression during OGTT compared to $50 \%(9 / 18)$ in the control group, $P=0.70$ (Table 4 ).

\section{Diabetes insipidus}

Four patients had DI preoperatively. In one patient, this disappeared after surgery. Overall, 18\% (12/67) patients required postsurgical desmopressin treatment permanently in the iMRI group vs $23 \%(26 / 113)$ in the control group. Transient postoperative SIADH was found in $11 \%(7 / 67)$ in the iMRI group vs $2.7 \%(3 / 109)$ in the control group, a significant difference, $P=0.026$.

\section{Vision}

In the iMRI group, 32\% (19/59) patients showed vision improvement, ranging from improvement in presurgical visual field deficiencies to intact vision, postoperatively compared to $31 \%(30 / 98)$ in the control group. $5 \%$ $(3 / 59)$ of cases experienced worsened vision, ranging from visual field deficiencies to central vision defects, postoperatively in the iMRI group compared to $4 \%(4 / 99)$ cases in the control group. Among cases with preoperative central vision impairment, 67\% (2/3) patients showed improvements in the iMRI group compared to $70 \%(7 / 10)$ in the control group.

Stratifying change in vision according to the Hardy classification grades B and C (data shown in Table 5), also revealed no statistically significant differences between iMRI and controls $(P=0.2$ and $P=0.65)$. 
Table 2 Tumor volume, resection and complications.

Preoperative $\left(\mathrm{cm}^{3}\right)(95 \% \mathrm{Cl})$
No tumor remnant, $n(\%)$
Tumor remnant
Postoperative $\left(\mathrm{cm}^{3}\right)(95 \% \mathrm{Cl})$
$\Delta$-Volume $\left(\mathrm{cm}^{3}\right)(95 \% \mathrm{Cl})$
Duration of surgery (mean in min) $(95 \% \mathrm{Cl})$
Complications after 30 days
Deep venous thrombosis (DVT)
Lung emboli $(n)(\%)$
Rhinoliquorrhea $(n)(\%)$
Meningitis $(n)(\%)$
Hematoma
Hemorrhage
Apoplexy
Other
Lumbar drain
Pneumo- or hydrocephalus with external cerebral drain
CNS infection
Liquorfistel operation
SIADH after surgery

\section{Discussion}

\section{Surgery}

In the present study, we found no significant differences between use and non-use of low field iMRI during surgery for PAs. Our results were in contrast to previous findings, where the use of low field iMRI increased the likelihood of GTR by 3-33\% (19). The lack of effect of low field iMRI on GTR in the present study could be due to (1) the image quality and resolution of a low field iMRI (0.15 T) not being adequate for evaluating tumor remnant after pituitary surgery, (2) an identified remnant on iMRI, does not necessarily make it possible to remove it without undue risk for the patient or (3) the interpretation of

\begin{tabular}{c}
\hline iMRI $(n=66)$ \\
\hline $7.5(5.32-9.58)$ \\
$10(15)$ \\
$56(85)$ \\
$2.97(0.94-5.01)$ \\
$4.52(3.56-5.49)$ \\
$127(118-136)$ \\
$21(31.8)$ \\
0 \\
$2(2.9)$ \\
$10(14.7)$ \\
$3(4.4)$ \\
0 \\
0 \\
0 \\
$10(16.2)$ \\
4 \\
1 \\
3 \\
2 \\
$7(10.8)$
\end{tabular}

\begin{tabular}{c}
\hline Control $(n=109)$ \\
\hline $7.16(6.02-8.31)$ \\
$26(23)$ \\
$83(77)$ \\
$2.09(1.58-2.6)$ \\
$5.11(4.2-6.03)$ \\
$96(91-101)$ \\
$35(30.7)$ \\
0 \\
$3(2.5)$ \\
$11(11.7)$ \\
$3(3.3)$ \\
$2(1.7)$ \\
$2(1.7)$ \\
0 \\
$20(20)$ \\
4 \\
4 \\
3 \\
3 \\
$3(2.7)$ \\
\end{tabular}

\begin{tabular}{c}
\hline P value \\
\hline 0.8 \\
0.26 \\
0.17 \\
0.3 \\
0.4 \\
$<0.0001$ \\
0.87 \\
0.86 \\
0.55 \\
0.71 \\
\\
\\
\\
\\
\end{tabular}

postoperative MRI was performed by neurosurgical personnel and not by a neuroradiologist.

Although surgery was performed by the same two neurosurgeons, the relatively low number of patients without PA remnant on the first postoperative control MRI may reflect the relatively low case volume. In contrast to our findings, this should, however, argue for a positive effect of the iMRI technique. Today the case volume is higher and the endoscopic surgical technique was introduced in January 2016 with both surgeons operating in collaboration. These results are being analyzed and compared to the traditional method described in this study.

Duration of surgery was prolonged to $126 \mathrm{~min}$ (range: 117-135) in the iMRI group compared to the control

Table 3 Tumor volume by Knosp classification.

\begin{tabular}{|c|c|}
\hline & iMRI \\
\hline & Right/left \\
\hline \multicolumn{2}{|l|}{ Pre op volume } \\
\hline $0-2\left(\mathrm{~cm}^{3}\right)$ & $5.2 / 5.7$ \\
\hline $3-4\left(\mathrm{~cm}^{3}\right)$ & $14.0 / 12.1$ \\
\hline \multicolumn{2}{|l|}{ GTR } \\
\hline $0-2(n=125)(\%)$ & $9(18.4) / 9(18.4$ \\
\hline $3-4(n=49)(\%)$ & $1(5.9) / 1(5.9)$ \\
\hline \multicolumn{2}{|l|}{ Remnant volume } \\
\hline $0-2\left(\mathrm{~cm}^{3}\right)$ & $1.6 / 1.9$ \\
\hline $3-4\left(\mathrm{~cm}^{3}\right)$ & $6.9 / 5.8$ \\
\hline \multicolumn{2}{|l|}{$\Delta$-Volume } \\
\hline $0-2\left(\mathrm{~cm}^{3}\right)$ & $3.7 / 3.9$ \\
\hline $3-4\left(\mathrm{~cm}^{3}\right)$ & $7.0 / 6.3$ \\
\hline
\end{tabular}

\begin{tabular}{c}
\hline Control \\
\hline Right/left \\
\hline $5.1 / 5.2$ \\
$12.2 / 12.7$ \\
$19(25.0) / 22(27.9)$ \\
$6(18.8) / 3(10.3)$ \\
$1.4 / 1.4$ \\
$3.7 / 3.9$ \\
$3.7 / 3.8$ \\
$8.5 / 8.7$ \\
\hline
\end{tabular}

\begin{tabular}{c}
\hline P value \\
\hline Right/left \\
\hline \\
$0.84 / 0.50$ \\
$0.56 / 0.86$ \\
\\
$0.39 / 0.25$ \\
$0.22 / 0.57$ \\
$0.63 / 0.27$ \\
$0.26 / 0.50$ \\
$0.90 / 0.95$ \\
$0.39 / 0.14$
\end{tabular}

0-2: Knosp classification 0, 1 or 2. 3-4: Knosp classification 3a, 3b or 4 .

$$
\begin{array}{lr}
\text { http://www.endocrineconnections.org } & \text { ○ } 2018 \text { The authors } \\
\text { https://doi.org/10.1530/EC-18-0140 } & \text { Published by Bioscientifica Ltd }
\end{array}
$$




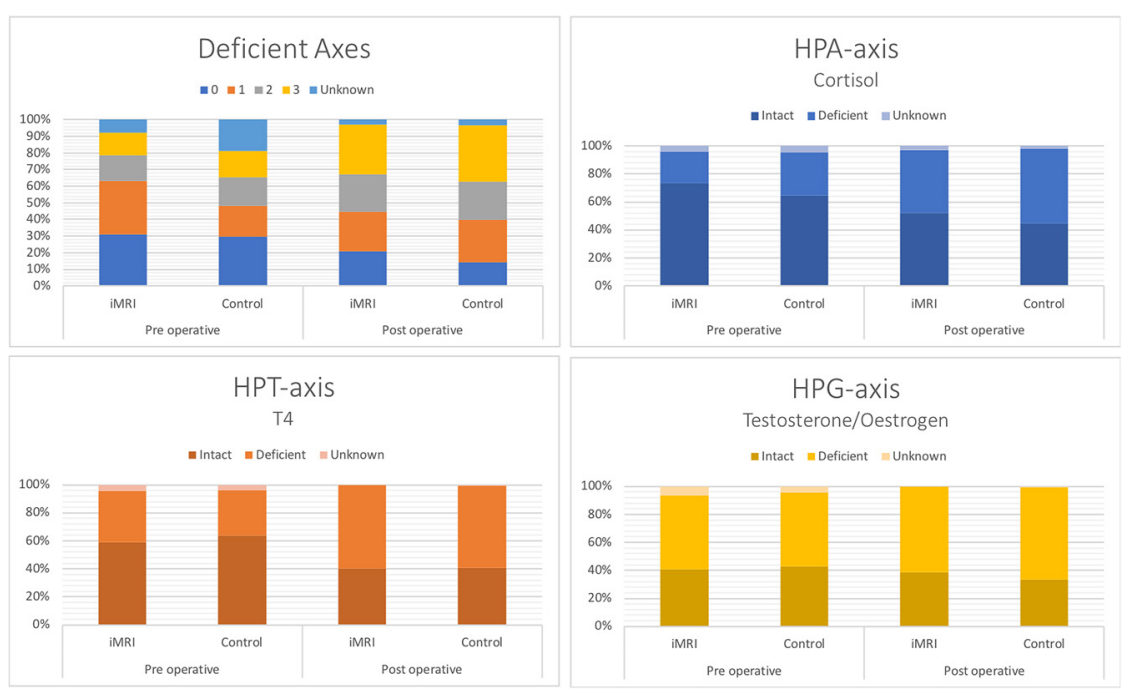

Figure 3

Deficient axes and specific axis function.

Table 4 Postoperative pituitary function.

\begin{tabular}{|c|c|c|c|c|c|}
\hline & \multicolumn{2}{|c|}{ iMRI $(n=67)$} & \multicolumn{2}{|c|}{ Control $(n=113)$} & Total \\
\hline \multicolumn{6}{|l|}{ HPA axis (\%) } \\
\hline Intact & \multicolumn{2}{|c|}{$35(52)$} & \multicolumn{2}{|c|}{$50(44.3)$} & $85(47.2)$ \\
\hline Unknown & \multicolumn{2}{|c|}{$2(3)$} & \multicolumn{2}{|c|}{$2(1.8)$} & $4(2.2)$ \\
\hline Increase & \multicolumn{2}{|c|}{0} & \multicolumn{2}{|c|}{$1(0.9)$} & $1(0.6)$ \\
\hline \multicolumn{6}{|l|}{ HPT axis (\%) } \\
\hline Intact & \multicolumn{2}{|c|}{$27(40.3)$} & \multicolumn{2}{|c|}{$45(39.8)$} & $72(40)$ \\
\hline Deficient & \multicolumn{2}{|c|}{$40(59.7)$} & \multicolumn{2}{|c|}{$65(57.5)$} & $105(58.4)$ \\
\hline Increase & \multicolumn{2}{|c|}{0} & \multicolumn{2}{|c|}{$2(1.7)$} & $2(1.1)$ \\
\hline Unknown & \multicolumn{2}{|c|}{0} & \multicolumn{2}{|c|}{$1(0.9)$} & $1(0.6)$ \\
\hline \multicolumn{6}{|l|}{ HPG axis (\%) } \\
\hline Intact & \multicolumn{2}{|c|}{$26(38.8)$} & \multicolumn{2}{|c|}{$38(33.6)$} & $64(35.6)$ \\
\hline Deficient & \multicolumn{2}{|c|}{$41(61.2)$} & \multicolumn{2}{|c|}{$74(65.5)$} & $115(65)$ \\
\hline Unknown & \multicolumn{2}{|c|}{0} & & .9) & $1(0.6)$ \\
\hline ADH function (\%) & & & & & \\
\hline Deficient & 12 & $.9)$ & & 3) & 38 (21.1) \\
\hline Unknown & 0 & & & .6) & $4(2.3)$ \\
\hline Deficient axes (\%) & & & & & \\
\hline 0 & 14 & $.9)$ & & 4.2) & $30(16.7)$ \\
\hline 1 & 16 & $.9)$ & & $5.7)$ & $45(25)$ \\
\hline 2 & 15 & .4) & & & $41(22.8)$ \\
\hline 3 & 20 & .9) & & 3.6) & $58(32.2)$ \\
\hline Unknown & 2 & & & .5) & $6(3.3)$ \\
\hline & & & & trol & \\
\hline & Intact & Deficient & Intact & Deficient & $P$ values \\
\hline Post op control & & & & & \\
\hline HPA axis, pre op intact $n=114(\%)$ & $31(63.3)$ & $17(34.7)$ & $43(65.2)$ & $23(34.8)$ & 0.95 \\
\hline HPT axis, pre op intact $n=108(\%)$ & $26(66.7)$ & $13(33.3)$ & $41(59.4)$ & $28(40.6)$ & 0.46 \\
\hline If deficient pre op, $n=15$ & $2(40)$ & $3 *(60)$ & $2(20)$ & $8(80)$ & 0.41 \\
\hline Testosterone level pre op, $n=72$ & $8(33.3)$ & $16(66.7)$ & $19(39.6)$ & $29(60.4)$ & 0.61 \\
\hline Intact, $n=33$ & $6(75)$ & $4(25)$ & $13(68.4)$ & $10(34.5)$ & 0.85 \\
\hline Deficient, 39 & $2(25)$ & $12(75)$ & $6(31.6)$ & $19(65.5)$ & 0.47 \\
\hline & Secreting & Non-secreting & Secreting & Non-secreting & \\
\hline GH-secreting adenomas, $n=29$ & $7(63.6)$ & $4(36.4)$ & $9(50)$ & $9(50)$ & 0.70 \\
\hline *1 Female with Hormonspiral. & & & & & \\
\hline $\begin{array}{l}\text { http://www.endocrineconnections.org } \\
\text { https://doi.org/10.1530/EC-18-0140 }\end{array}$ & $\begin{array}{l}18 \text { The authors } \\
\text { oscientifica Ltd }\end{array}$ & & $\begin{array}{l}\text { This w } \\
\text { Attrib }\end{array}$ & $\begin{array}{l}\text { is licensed under a } \mathrm{Cr} \\
\text { n } 4.0 \text { International } \mathrm{Li}\end{array}$ & $\begin{array}{l}\text { ive Commons } \\
\text { se. }\end{array}$ \\
\hline
\end{tabular}


Table 5 Vision by Hardy classification.

\begin{tabular}{|c|c|c|c|}
\hline Suprasellar expansion & IMRI & Control & $P$ values \\
\hline Overall & $(n=64)$ & $(n=99)$ & \\
\hline \multicolumn{4}{|l|}{ Right eye } \\
\hline Impaired field pre (\%) & $43(67.2)$ & $60(60.6)$ & \\
\hline Improved & 19 (44.2) & $23(38.3)$ & 0.55 \\
\hline Unchanged & $21(48.8)$ & $34(56.7)$ & 0.43 \\
\hline Worsened & $1(1.7)$ & 0 & NA \\
\hline Intact pre & $21(32.8)$ & $39(39.4)$ & \\
\hline Unchanged & $16(76.2)$ & $30(76.9)$ & 0.98 \\
\hline Worsened & $2(9.5)$ & $4(10.3)$ & 0.93 \\
\hline Impaired central pre & $3(4.7)$ & $10(9.9)$ & \\
\hline Improved & $2(66.6)$ & $7(70)$ & 0.96 \\
\hline \multicolumn{4}{|l|}{ Left eye } \\
\hline Impaired field pre (\%) & $45(70.3)$ & $62(62.6)$ & \\
\hline Improved & $16(35.6)$ & $17(27.4)$ & 0.37 \\
\hline Unchanged & $26(57.8)$ & $42(67.7)$ & 0.29 \\
\hline Worsened & $1(1.8)$ & $1(1)$ & 0.82 \\
\hline Intact pre & $18(28.1)$ & $32(32.3)$ & \\
\hline Unchanged & $14(77.8)$ & $26(81.3)$ & 0.92 \\
\hline Worsened & $1(5.6)$ & $2(6.3)$ & 0.92 \\
\hline Impaired central pre & $3(4.6)$ & $12(12.1)$ & \\
\hline Improved & $2(66.6)$ & $7(58.3)$ & 0.9 \\
\hline Hardy grade B & $(n=28)$ & $(n=45)$ & \\
\hline \multicolumn{4}{|l|}{ Right eye } \\
\hline Impaired field pre (\%) & $22(81.5)$ & $30(66.7)$ & \\
\hline Improved & $12(54.6)$ & $11(36.7)$ & 0.2 \\
\hline Unchanged & $8(36.4)$ & $18(60)$ & 0.09 \\
\hline Worsened & 0 & $1(2.2)$ & NA \\
\hline Intact pre & $5(17.9)$ & $15(33.3)$ & \\
\hline Unchanged & $5(100)$ & $12(80)$ & 0.76 \\
\hline Worsened & 0 & 0 & \\
\hline Impaired central pre & $2(7.4)$ & $4(8.9)$ & \\
\hline Improved & $1(50)$ & $3(75)$ & 0.78 \\
\hline \multicolumn{4}{|l|}{ Left eye } \\
\hline Impaired field pre (\%) & $23(82.1)$ & $33(73.3)$ & \\
\hline Improved & $10(43.5)$ & $9(27.3)$ & 0.21 \\
\hline Unchanged & $11(47.8)$ & $22(66.7)$ & 0.16 \\
\hline Worsened & $1(4.3)$ & $1(2.2)$ & 0.8 \\
\hline Intact pre & $4(14.3)$ & $11(24.4)$ & \\
\hline Unchanged & $4(100)$ & $10(90.9)$ & 0.91 \\
\hline Worsened & 0 & 0 & \\
\hline Impaired central pre & $3(10.7)$ & $3(6.7)$ & \\
\hline Improved & 0 & 0 & NA \\
\hline Hardy grade C & $(n=18)$ & $(n=22)$ & \\
\hline \multicolumn{4}{|l|}{ Right eye } \\
\hline Impaired field pre (\%) & $14(77.8)$ & $19(86.4)$ & \\
\hline Improved & $4(28.6)$ & $7(36.8)$ & 0.61 \\
\hline Unchanged & $10(71.4)$ & $10(52.6)$ & 0.27 \\
\hline Worsened & $1(5.6)$ & 0 & NA \\
\hline Intact pre & $3(16.7)$ & $2(9.1)$ & \\
\hline Unchanged & $2(66.7)$ & $2(100)$ & 0.76 \\
\hline Worsened & $1(33.3)$ & 0 & NA \\
\hline Impaired central pre & $1(5.6)$ & $5(22.7)$ & \\
\hline Improved & $1(100)$ & $3(60)$ & 0.75 \\
\hline \multicolumn{4}{|l|}{ Left eye } \\
\hline Impaired field pre & $16(88.9)$ & $20(90.9)$ & \\
\hline Improved & $3(18.8)$ & $5(25)$ & 0.65 \\
\hline Unchanged & $13(81.3)$ & $14(70)$ & 0.5 \\
\hline Worsened & 0 & 0 & \\
\hline Intact pre & 0 & 0 & \\
\hline Impaired central pre & 0 & $7(31.8)$ & \\
\hline Improved & 0 & $4(57.1)$ & NA \\
\hline
\end{tabular}

http://www.endocrineconnections.org https://doi.org/10.1530/EC-18-0140 group (98 min, range: $92-103), P$-value $<0.001$. This is comparable with previous findings $(11,20,21)$.

The largest study on 229 PAs applying iMRI in pituitary surgery (16) reported that 20.5\% (47/229) cases had a tumor remnant, which was eligible for further resection. In contrast to the present study, the 229 patients were selected for the use of iMRI due to large tumors, with extensive suprasellar or retro/parasellar expansion and no controls were included (16). In addition, no volumetric analysis of the tumor volume preoperatively or postoperatively was performed (16). Hence, the selection of study participants and lack of data on the size of tumor volume may have influenced the results.

In a review paper on $0.15 \mathrm{~T}$ iMRI (20), no increase in GTR was described in two out of five studies. Our study showed an 18.4\% GTR in Knosp grade 0-2 and a 5.9\% GTR in Knosp grade 3-4 cases, with no statistically significant difference between iMRI and controls. Better resection of less invasive adenomas by the use of iMRI is, however, supported by findings in previous studies $(16,22,23)$.

Transsphenoidal surgery is considered relatively safe, and accordingly, we did not experience severe complications in this study. However, duration of surgery in the iMRI group was increased by approximately $30 \mathrm{~min}$ compared to the controls ( $P$ value $<0.001$ ). The longer duration did not result in any significant differences in the rate of complications between the groups, even when considering the three excluded cases, having transcranial surgery due to postoperative acute complications. This is also comparable with a previous study (19).

Because of introduction of new equipment, the iMRI, a learning curve might have been expected during the first year. However, there was no statistically significant difference in duration of surgery, tumor remnant volume and complication rates when comparing surgeries performed during the first year of iMRI and later (data not shown).

\section{Pituitary function}

There was no difference in postoperative pituitary function with or without the use of iMRI. 35\% (17/48) in the iMRI group vs 38\% (23/63) in the control group developed HPA-axis deficiency. Similarly, 33\% (13/39) developed HPT-axis deficiency in the iMRI group vs $41 \%(28 / 69)$ in the control group. These findings are similar to a previous study (11). Postoperative HPA-axis deficiency is concluded based on an insufficient response to a Synacthen test (24) while central hypothyroidism is based on low T4 combined with a (sub)normal TSH (25).

This work is licensed under a Creative Commons Attribution 4.0 International License.

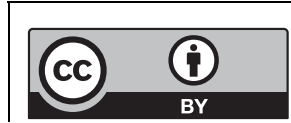


In a study by Berkmann et al. (17), an insignificant difference was found between iMRI and controls in both HPA (15\% vs 13\%) and HPT (18\% vs 13\%) axes, respectively.

Overall, 15\% (7/47) of the cases showed remission of HPA-axis function, comparable to previously published rates of $16-41 \%(7,26)$; however, their results were only based on NFPAs. HPT-axis remission was lower in our study where only $1.7 \%(1 / 60)$ cases regained function compared to previous studies reporting that $7-14 \%(7,26)$ of the patients normalized function. Postoperatively, $18 \%$ $(12 / 67)$ in the iMRI group presented with DI, compared to $23 \%(26 / 113)$ in the control group. This was slightly higher than previous published studies $(0.5-15 \%)(13,14)$.

Interestingly, there was a tendency for patients with both intact HPA and HPT axes postoperatively to have a lower surgical reduction in adenoma volume. Although not statistically significant, this suggests that higher degree of surgical resection is associated with a higher risk of postoperative pituitary insufficiency. Further studies are needed to clarify this.

We found no effect of using low field iMRI regarding GH-secreting adenomas $(P=0.70)$. Remission of $\mathrm{GH}$ secretion was $45 \%(13 / 29)$, which showed that even a small tumor remnant not visualized on $0.15 \mathrm{~T}$ iMRI was capable of GH hypersecretion. In contrast to our findings, iMRI was found favorable for complete resection of GH-secreting adenomas in a previous study (27).

In total, $14 \%(4 / 29)$ of the GH-secreting adenomas were microadenomas. However, in our experience, low field iMRI has a limited role for microadenomas surgery, since GH-microadenomas are too small to be visualized using a $0.15 \mathrm{~T}$ iMRI.

\section{Vision}

In the present study, 32\% (19/59) cases in the iMRI group showed improvement of preoperative deficiency in field of vision. This is less than reported in a recent study on 47 patients by Luomaranta et al. (28) where a 50\% remission to normal vision was found. However, in Luomarantas study, three patients were excluded due to deterioration of vision after surgery. Our study showed worsened vision in 7 of 165 (4\%) patients who were able to participate in the assessment of field vision deficiencies. These issues considered, the risk of impaired vision after PA surgery seems to be consistent throughout the literature and comparable to the results of the present study. This is further substantiated by a study by Wu et al. (20), where they found worsened vision in 3\% of cases after surgery.

\section{Limitations and strengths}

This study evaluated the effects of the use of iMRI in transsphenoidal operations on PAs. Patients were selected by surgical procedure only. A few cases were discarded due to lack of availability of both a preoperative MRI scan or an available description of the surgical procedure. These inclusion criteria resulted in a highly diverse but very representative group of patients with PAs. Furthermore, all patients were operated by the same two surgeons.

\section{Conclusion}

Use of intraoperative low field MRI in transsphenoidal pituitary surgery was not associated with increased GTR or reduced volume of tumor remnants. The duration of surgery was prolonged when iMRI was used, but it was not associated with increased infection rates. Changes in postoperative pituitary function and visual fields were comparable.

\section{Supplementary data}

This is linked to the online version of the paper at https://doi.org/10.1530/ EC-18-0140.

\section{Declaration of interest}

The authors declare that there is no conflict of interest that could be perceived as prejudicing the impartiality of the research reported.

\section{Funding}

This study was funded by Lundbeck Foundation, through the Danish Neurosurgical Society (DNKS)

\section{Acknowledgement}

The help and assistance from the Department of Neurosurgery and the Department of Endocrinology and OPEN, Odense Patient data Explorative Network, Odense University Hospital, Odense, Denmark is greatly appreciated.

\section{References}

1 Asa SL \& Ezzat S. The pathogenesis of pituitary tumors. Annual Review of Pathology 20094 97-126. (https://doi.org/10.1146/annurev. pathol.4.110807.092259)

2 Aflorei ED \& Korbonits M. Epidemiology and etiopathogenesis of pituitary adenomas. Journal of Neuro-Oncology 2014117 379-394. (https://doi.org/10.1007/s11060-013-1354-5)

3 Surawicz TS, McCarthy BJ, Kupelian V, Jukich PJ, Bruner JM \& Davis FG. Descriptive epidemiology of primary brain and CNS tumors: results from the Central Brain Tumor Registry of the United States, 1990-1994. Neuro-Oncology 19991 14-25. (https://doi. org/10.1093/neuonc/1.1.14)

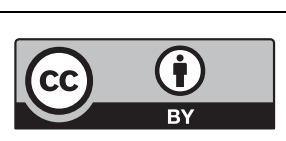

This work is licensed under a Creative Commons Attribution 4.0 International License. 
4 Di Ieva A, Rotondo F, Syro LV, Cusimano MD \& Kovacs K. Aggressive pituitary adenomas - diagnosis and emerging treatments. Nature Reviews Endocrinology 201410 423-435. (https://doi.org/10.1038/ nrendo.2014.64)

5 Hardy J \& Vezina JL. Transsphenoidal neurosurgery of intracranial neoplasm. Advances in Neurology 197615 261-273.

6 Micko AS, Wohrer A, Wolfsberger S \& Knosp E. Invasion of the cavernous sinus space in pituitary adenomas: endoscopic verification and its correlation with an MRI-based classification. Journal of Neurosurgery 2015122 803-811. (https://doi.org/10.3171/2014.12. JNS141083)

7 Fatemi N, Dusick JR, Mattozo C, McArthur DL, Cohan P, Boscardin J, Wang C, Swerdloff RS \& Kelly DF. Pituitary hormonal loss and recovery after transsphenoidal adenoma removal. Neurosurgery 200863 709-718; discussion 18-19. (https://doi.org/10.1227/01. NEU.0000325725.77132.90)

8 Barzaghi LR, Medone M, Losa M, Bianchi S, Giovanelli M \& Mortini P. Prognostic factors of visual field improvement after transsphenoidal approach for pituitary macroadenomas: review of the literature and analysis by quantitative method. Neurosurgical Review 201235 369-378; discussion 78-79. (https://doi.org/10.1007/s10143011-0365-y)

9 Hardy J. Excision of pituitary adenomas by trans-sphenoidal approach. L'Union Medicale du Canada 196291 933-945.

10 Black PM, Moriarty T, Alexander E 3rd, Stieg P, Woodard EJ, Gleason PL, Martin CH, Kikinis R, Schwartz RB \& Jolesz FA. Development and implementation of intraoperative magnetic resonance imaging and its neurosurgical applications.

Neurosurgery 199741 831-842; discussion 42-45. (https://doi. org/10.1097/00006123-199710000-00013)

11 Coburger J, Konig R, Seitz K, Bazner U, Wirtz CR \& Hlavac M. Determining the utility of intraoperative magnetic resonance imaging for transsphenoidal surgery: a retrospective study. Journal of Neurosurgery 2014120 346-356. (https://doi.org/10.3171/2013.9. JNS122207)

12 Rao G. Intraoperative MRI and maximizing extent of resection. Neurosurgery Clinics of North America 201728 477-485. (https://doi. org/10.1016/j.nec.2017.05.003)

13 Sudhakar N, Ray A \& Vafidis JA. Complications after trans-sphenoidal surgery: our experience and a review of the literature. British Journal of Neurosurgery 200418 507-512. (https://doi.org/10.1080/02688690 400012459a)

14 Aulinas A, Colom C, Ybarra J, Munoz F, Tresserras P, Resmini E $\&$ Webb SM. Immediate and delayed postoperative morbidity in functional and non-functioning pituitary adenomas. Pituitary 2012 15 380-385. (https://doi.org/10.1007/s11102-011-0331-2)

15 Lopes MBS. The 2017 World Health Organization classification of tumors of the pituitary gland: a summary. Acta Neuropathologica 2017 134 521-535. (https://doi.org/10.1007/s00401-017-1769-8)

16 Kim EH, Oh MC \& Kim SH. Application of low field intraoperative magnetic resonance imaging in transsphenoidal surgery for pituitary adenomas: technical points to improve the visibility of the tumor resection margin. Acta Neurochirurgica 2013155 485-493. (https:// doi.org/10.1007/s00701-012-1608-6)

17 Berkmann S, Fandino J, Muller B, Remonda L \& Landolt H. Intraoperative MRI and endocrinological outcome of transsphenoidal surgery for non-functioning pituitary adenoma. Acta Neurochirurgica 2012154 639-647. (https://doi.org/10.1007/s00701-012-1285-5)
18 Harris PA, Taylor R, Thielke R, Payne J, Gonzalez N \& Conde JG. Research electronic data capture (REDCap) - a metadata-driven methodology and workflow process for providing translational research informatics support. Journal of Biomedical Informatics 2009 42 377-381. (https://doi.org/10.1016/j.jbi.2008.08.010)

19 Patel KS, Yao Y, Wang R, Carter BS \& Chen CC. Intraoperative magnetic resonance imaging assessment of non-functioning pituitary adenomas during transsphenoidal surgery. Pituitary 201619 222-231. (https://doi.org/10.1007/s11102-015-0679-9)

20 Wu JS, Shou XF, Yao CJ, Wang YF, Zhuang DX, Mao Y, Li SQ \& Zhou LF. Transsphenoidal pituitary macroadenomas resection guided by PoleStar N20 low-field intraoperative magnetic resonance imaging: comparison with early postoperative high-field magnetic resonance imaging. Neurosurgery 2009 65 63-70; discussion -1. (https://doi.org/10.1227/01. NEU.0000348549.26832.51)

21 Gerlach R, du Mesnil de Rochemont R, Gasser T, Marquardt G, Reusch J, Imoehl L \& Seifert V. Feasibility of Polestar N20, an ultralow-field intraoperative magnetic resonance imaging system in resection control of pituitary macroadenomas: lessons learned from the first 40 cases. Neurosurgery 200863 272-284; discussion 84-85. (https://doi.org/10.1227/01.NEU.0000312362.63693.78)

22 Pala A, Knoll A, Brand C, Etzrodt-Walter G, Coburger J, Wirtz CR $\&$ Hlavac M. The value of intraoperative MRI in endoscopic and microsurgical transsphenoidal pituitary adenoma resection. World Neurosurgery 2017102 144-150. (https://doi.org/10.1016/j. wneu.2017.02.132)

23 Dallapiazza RF, Grober Y, Starke RM, Laws ER Jr \& Jane JA Jr Longterm results of endonasal endoscopic transsphenoidal resection of nonfunctioning pituitary macroadenomas. Neurosurgery 201576 42-52; discussion -3. (https://doi.org/10.1227/ NEU.0000000000000563)

24 Klose M, Lange M, Kosteljanetz M, Poulsgaard L \& FeldtRasmussen U. Adrenocortical insufficiency after pituitary surgery: an audit of the reliability of the conventional short synacthen test. Clinical Endocrinology 200563 499-505. (https://doi.org/10.1111/ j.1365-2265.2005.02368.x)

25 Klose M, Marina D, Hartoft-Nielsen ML, Klefter O, Gavan V, Hilsted L, Rasmussen AK \& Feldt-Rasmussen U. Central hypothyroidism and its replacement have a significant influence on cardiovascular risk factors in adult hypopituitary patients. Journal of Clinical Endocrinology and Metabolism 201398 3802-3810. (https:// doi.org/10.1210/jc.2013-1610)

26 Comtois R, Beauregard H, Somma M, Serri O, Aris-Jilwan N $\&$ Hardy J. The clinical and endocrine outcome to transsphenoidal microsurgery of nonsecreting pituitary adenomas. Cancer 199168 860-866. (https://doi.org/10.1002/10970142(19910815)68:4<860::AID-CNCR2820680431>3.0.CO;2-4)

27 Netuka D, Májovský M, Masopust V, Belšán T, Marek J, Kršek M, Hána V, Ježková J, Hána V \& Beneš V. Intraoperative magnetic resonance imaging during endoscopic transsphenoidal surgery of growth hormone-secreting pituitary adenomas. World Neurosurgery 201691 490-496. (https://doi.org/10.1016/j. wneu.2016.04.094)

28 Luomaranta T, Raappana A, Saarela V \& Liinamaa MJ. Factors affecting the visual outcome of pituitary adenoma patients treated with endoscopic transsphenoidal surgery. World Neurosurgery 2017 105 422-431. (https://doi.org/10.1016/j.wneu.2017.05.144)
Received in final form 22 June 2018

Accepted 28 June 2018

Accepted Preprint published online 2 July 2018 http://www.endocrineconnections.org https://doi.org/10.1530/EC-18-0140 (c) 2018 The authors Published by Bioscientifica Ltd

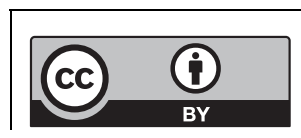

This work is licensed under a Creative Commons Attribution 4.0 International License. 